Virginia Commonwealth University vCU Scholars Compass

2012

\title{
Peripheral-Blood Stem Cells versus Bone Marrow from Unrelated Donors
}

\author{
Claudio Anasetti \\ H. Lee Moffitt Cancer Center and Research Institute
}

Brent R. Logan

Medical College of Wisconsin

Stephanie J. Lee

Fred Hutchinson Cancer Research Center

See next page for additional authors

Follow this and additional works at: http://scholarscompass.vcu.edu/massey_pubs

Part of the Medicine and Health Sciences Commons

From The New England Journal of Medicine, Anasetti, C., Logan, B. R., Lee, S.J. et al., Peripheral-Blood Stem Cells versus Bone Marrow from Unrelated Donors, Vol. 367, Page 1487, Copyright (C) 2012 Massachusetts Medical Society.

\section{Downloaded from}

http://scholarscompass.vcu.edu/massey_pubs/6

This Article is brought to you for free and open access by the Massey Cancer Center at VCU Scholars Compass. It has been accepted for inclusion in Massey Cancer Center Publications by an authorized administrator of VCU Scholars Compass. For more information, please contact libcompass@vcu.edu. 


\section{Authors}

Claudio Anasetti, Brent R. Logan, Stephanie J. Lee, Edmund K. Waller, Daniel J. Weisdorf, John R. Wingard, Corey S. Cutler, Peter Westervelt, Ann Woolfrey, Stephen Couban, Gerhard Ehninger, Laura Johnston, Richard T. Maziarz, Michael A. Pulsipher, David L. Porter, Shin Mineishi, John M. McCarty, Shakila P. Khan, Paolo Anderlini, William I. Bensinger, Susan F. Leitman, Scott D. Rowley, Christopher Bredeson, Shelly L. Carter, Mary M. Horowitz, and Dennis L. Confer 


\title{
The NEW ENGLAN D \\ JOURNAL of MEDICINE
}

ESTABLISHED IN 1812

OCTOBER 18, 2012

VOL. 367 NO. 16

\section{Peripheral-Blood Stem Cells versus Bone Marrow from Unrelated Donors}

\author{
Claudio Anasetti, M.D., Brent R. Logan, Ph.D., Stephanie J. Lee, M.D., M.P.H., Edmund K. Waller, M.D., Ph.D., \\ Daniel J. Weisdorf, M.D., John R. Wingard, M.D., Corey S. Cutler, M.D., M.P.H., Peter Westervelt, M.D., Ph.D., \\ Ann Woolfrey, M.D., Stephen Couban, M.D., Gerhard Ehninger, M.D., Laura Johnston, M.D., Richard T. Maziarz, M.D., \\ Michael A. Pulsipher, M.D., David L. Porter, M.D., Shin Mineishi, M.D., John M. McCarty, M.D., Shakila P. Khan, M.D., \\ Paolo Anderlini, M.D., William I. Bensinger, M.D., Susan F. Leitman, M.D., Scott D. Rowley, M.D., \\ Christopher Bredeson, M.D., Shelly L. Carter, Sc.D., Mary M. Horowitz, M.D., and Dennis L. Confer, M.D., \\ for the Blood and Marrow Transplant Clinical Trials Network**
}

\section{ABSTRACT}

\section{BACKGROUND}

Randomized trials have shown that the transplantation of filgrastim-mobilized peripheral-blood stem cells from HLA-identical siblings accelerates engraftment but increases the risks of acute and chronic graft-versus-host disease (GVHD), as compared with the transplantation of bone marrow. Some studies have also shown that peripheral-blood stem cells are associated with a decreased rate of relapse and improved survival among recipients with high-risk leukemia.

\section{METHODS}

We conducted a phase 3, multicenter, randomized trial of transplantation of peripheral-blood stem cells versus bone marrow from unrelated donors to compare 2-year survival probabilities with the use of an intention-to-treat analysis. Between March 2004 and September 2009, we enrolled 551 patients at 48 centers. Patients were randomly assigned in a 1:1 ratio to peripheral-blood stem-cell or bone marrow transplantation, stratified according to transplantation center and disease risk. The median follow-up of surviving patients was 36 months (interquartile range, 30 to 37).

\section{RESULTS}

The overall survival rate at 2 years in the peripheral-blood group was 51\% (95\% confidence interval [CI], 45 to 57), as compared with $46 \%$ (95\% CI, 40 to 52) in the bone marrow group $(\mathrm{P}=0.29)$, with an absolute difference of 5 percentage points ( $95 \% \mathrm{CI},-3$ to 14). The overall incidence of graft failure in the peripheral-blood group was 3\% (95\% CI, 1 to 5), versus $9 \%$ (95\% CI, 6 to 13) in the bone marrow group $(\mathrm{P}=0.002)$. The incidence of chronic GVHD at 2 years in the peripheral-blood group was $53 \%$ (95\% CI, 45 to 61), as compared with $41 \%$ (95\% CI, 34 to 48 ) in the bone marrow group $(\mathrm{P}=0.01)$. There were no significant between-group differences in the incidence of acute GVHD or relapse.

\section{CONCLUSIONS}

We did not detect significant survival differences between peripheral-blood stem-cell and bone marrow transplantation from unrelated donors. Exploratory analyses of secondary end points indicated that peripheral-blood stem cells may reduce the risk of graft failure, whereas bone marrow may reduce the risk of chronic GVHD. (Funded by the National Heart, Lung, and Blood Institute-National Cancer Institute and others; ClinicalTrials.gov number, NCT00075816.)
From H. Lee Moffitt Cancer Center and Research Institute, Tampa (C.A.), and Shands Cancer Center, University of Florida, Gainesville (J.R.W.) - both in Florida; Medical College of Wisconsin, Milwaukee (B.R.L., M.M.H.); Fred Hutchinson Cancer Research Center, Seattle (S.J.L., A.W., W.I.B.); Winship Cancer Institute, Emory University, Atlanta (E.K.W.); University of Minnesota Medical Center, Minneapolis (D.J.W.), Mayo Clinic, Rochester (S.P.K.), and the National Marrow Donor Program, Minneapolis (D.L.C.) - all in Minnesota; DanaFarber Cancer Institute, Boston (C.S.C.); Siteman Cancer Center, Washington University, St. Louis (P.W.); Dalhousie University, Halifax, NS (S.C.), and Ottawa Hospital, Ottawa (C.B.) - both in Canada; University Hospital Dresden, Dresden, Germany (G.E.); Stanford University Medical Center, Stanford, CA (L.J.); Oregon Health and Science University, Portland (R.T.M.); Primary Children's Medical Center, University of Utah, Salt Lake City (M.A.P.); University of Pennsylvania, Philadelphia (D.L.P.); University of Michigan, Ann Arbor (S.M.); Massey Cancer Center, Virginia Commonwealth University, Richmond (J.M.M.); University of Texas M.D. Anderson Cancer Center, Houston (P.A.); National Institutes of Health, Bethesda (S.F.L.), and EMMES Corporation, Rockville (S.L.C.) - both in Maryland; and John Theurer Cancer Center, Hackensack University, Hackensack, NJ (S.D.R.). Address reprint requests to Dr. Anasetti at the Moffitt Cancer Center, 12902 Magnolia Dr., Tampa, FL 33612, or at claudio.anasetti@moffitt.org.

*Additional members of the Blood and Marrow Transplant Clinical Trials Network who contributed to this study are listed in the Supplementary Appendix, available at NEJM.org.

N EnglJ Med 2012;367:1487-96. DOI: 10.1056/NEJMoal203517 Copyright $(2012$ Massachusetts Medical Society. 
top

N THE EARLY DAYS OF ALLOGENEIC HEMAtopoietic stem-cell transplantation, the only graft source available was bone marrow harvested from the pelvis of a donor under anesthesia. When studies showed that an increased dose of bone marrow cells correlated with more robust hematopoietic engraftment and lower mortality from infectious complications, transplantation centers began to use filgrastim-stimulated peripheral blood, which has a much higher content of blood progenitor cells than bone marrow, although there was concern that the higher T-cell content might increase the risk of graft-versushost disease (GVHD). ${ }^{1-5}$ Several large, randomized trials of transplantation between HLA-identical siblings showed that peripheral-blood stem cells resulted in better engraftment but increased the risk of acute and chronic GVHD. ${ }^{4-11}$ Some studies showed a decreased rate of relapse and better survival with peripheral-blood stem cells, as compared with bone marrow, especially among patients with high-risk blood-cell cancers. However, the results obtained with transplants from HLA-identical siblings may not be applicable to transplants from unrelated donors, given the greater genetic diversity and, therefore, greater risk of GVHD in the unrelated recipient, even if the donor and recipient are fully HLA-matched.

Over the past decade, the use of peripheralblood stem cells has increased and now accounts for $75 \%$ of stem-cell transplants from unrelated adult donors, without clinical data to support this shift. ${ }^{12}$ A large observational study of unrelateddonor transplants showed higher rates of acute and chronic GVHD with peripheral-blood stem cells than with bone marrow and no improvement in survival. ${ }^{13}$ To determine the effects of graft source for unrelated-donor transplants, we performed a randomized trial comparing outcomes of peripheral-blood stem-cell and bone marrow transplantations.

\section{METHODS}

\section{STUDY DESIGN}

The study was an open-label, phase 3, multicenter, randomized trial conducted by the Blood and Marrow Transplant Clinical Trials Network. Randomization was performed in a 1:1 ratio, with the use of random block sizes, and was stratified according to transplantation center and disease risk. The target enrollment was 550 donor-recipient pairs. The primary end point was 2-year survival as assessed by means of an intention-to-treat analysis. Prespecified secondary end points included post-transplantation incidences of neutrophil and platelet engraftment, graft failure, acute and chronic GVHD, relapse, and infections. Other end points included adverse events, immune reconstitution, time to discontinuation of immunosuppressive therapy, and quality of life. This article focuses on the primary end point and clinical secondary end points. Analyses of immune reconstitution and quality of life are ongoing.

Enrollment began on March 31, 2004, and ended on September 9, 2009. The analysis included data collected as of November 15, 2011. The median follow-up of surviving patients is 36 months (interquartile range, 30 to 37). Patients were followed in the study for 3 years, with a late analysis at 5 years planned with the use of data from the Center for International Blood and Marrow Transplant Research, which tracks the outcomes of all allogeneic transplantations in the United States.

\section{PATIENTS}

Eligible patients were less than 66 years of age and were planning to undergo transplantation for acute leukemia, myelodysplasia, chronic myeloid or myelomonocytic leukemia, or myelofibrosis. These diseases accounted for approximately $75 \%$ of unrelated-donor transplantations in the United States during the study period. Exclusion criteria were donor-specific anti-HLA antibodies, prior allogeneic or autologous transplantation, human immunodeficiency virus infection, pregnancy or breast-feeding, cardiac insufficiency or coronary artery disease requiring treatment, active infection, or concomitant enrollment in a phase 1 study. Additional exclusion criteria were a serum level of creatinine, bilirubin, alanine aminotransferase, or aspartate aminotransferase that was greater than two times the upper limit of the normal range, as well as a forced vital capacity, forced expiratory volume in 1 second, or diffusing capacity of the lung for carbon monoxide that was less than $50 \%$ of the predicted value.

\section{TREATMENT}

The protocol required DNA typing of the patient and donor at intermediate resolution for HLA-A, $B$, and $C$ and at high resolution for $D R B 1$, as well as matching for five or six of the six HLA-A, B, and DRB1 antigens. All donors and recipients gave written informed consent before enrollment. Bone 
marrow cells were collected from the donors by means of standard procedures. Peripheral-blood stem-cell donors were prescribed filgrastim (at the North American centers) or lenograstim (at the German centers) at a dose of $10 \mu \mathrm{g}$ per kilogram of body weight per day for 5 days and underwent a single large-volume apheresis on day 5 or two smaller-volume apheresis procedures on days 5 and 6 . Bone marrow or peripheral-blood stem cells were not T-cell-depleted or cryopreserved before transplantation. No blinding was attempted.

Patients received one of four conditioning regimens (cyclophosphamide and total-body irradiation; cyclophosphamide and busulfan; fludarabine, busulfan, and antithymocyte globulin; or fludarabine and melphalan), with the minimum dose of each agent defined in the protocol (Table 1). The cyclophosphamide-containing regimens are myeloablative, whereas the fludarabine-containing regimens are reduced-intensity conditioning regimens. Patients received one of two GVHD-prophylaxis regimens (tacrolimus and methotrexate, or cyclosporine and methotrexate), with or without additional agents. Both the conditioning and GVHD-prophylaxis regimens had to be specified before randomization. Supportive care and treatment for GVHD were provided according to institutional standards. A committee of investigators who were unaware of the study assignments reviewed all case records, focusing on causes of death, relapse, acute and chronic GVHD, and graft failure. The protocol is available with the full text of this article at NEJM.org and on a public website (www.bmtctn.net).

A protocol review committee appointed by the National Heart, Lung, and Blood Institute approved the research protocol, which was also approved by local institutional review boards and ethics committees. All authors vouch for the accuracy and completeness of the reported data and analyses and for the adherence of the study to the protocol. The data and safety monitoring board appointed by the National Heart, Lung, and Blood Institute also reviewed the analyses.

\section{STATISTICAL ANALYSIS}

After accounting for an anticipated $5 \%$ of patients not undergoing transplantation, we calculated that the study would have $80 \%$ power to detect a difference of 12.5 percentage points in the 2-year survival rate between the two study groups (35.0\% and $47.5 \%$ ), with the use of a chi-square test and a two-sided alpha level of $5 \%$. There was no pre- defined anticipated direction of the survival difference between the two treatment groups. All patients who underwent randomization were included in the primary, intention-to-treat analysis of overall survival. Survival times were calculated from the date of randomization.

The primary analysis was planned as a pointwise comparison of overall survival at 2 years rather than as a log-rank test because of concerns about nonproportional hazards between the two groups. However, the final analyses did not show violations of hazard proportionality, and therefore, results of the Cox model are also presented. The primary comparison of 2-year survival was performed with the use of a stratified binomial comparison (Mantel-Haenszel test), stratified according to transplantation center and disease risk. Kaplan-Meier survival curves were constructed for each group.

For analyses of the secondary end points, data on transplantation-related events were collected only for patients who underwent transplantation, and event times were calculated from the date of transplantation. There was no explicit adjustment for multiple testing of secondary end points, and since the primary statistical hypothesis was not rejected, all the secondary analyses are considered exploratory. Results are presented according to study group. The rates of neutrophil and platelet engraftment, graft failure, acute GVHD, chronic GVHD, death in the absence of relapse, and relapse were compared between the two groups with the use of a stratified log-rank test that treated relapse as a competing event for death in the absence of relapse and treated death as a competing risk for all other end points. Cumulative incidence curves were estimated for each group. ${ }^{14}$ Chronic GVHD was classified as limited or extensive, as previously reported, ${ }^{15}$ because the study protocol was written before the National Institutes of Health workshop that redefined diagnostic and staging criteria for chronic GVHD. ${ }^{16}$

However, chronic GVHD did not include cases with sole manifestations of late acute GVHD that occurred more than 100 days after transplantation. Inclusion of these late cases in the analyses of acute GVHD did not change the results (data not shown). The probabilities of being alive and free of immunosuppressive treatment at 2 years were compared between the two study groups with the use of the chi-square test. Two-year rates of overall survival and disease-free survival since transplantation were compared between patients 
according to their randomly assigned treatment group with the use of a stratified MantelHaenszel test. In addition, a planned secondary analysis of outcomes was conducted with the use of Cox regression to adjust for the characteristics of the patients.

Covariates considered in the model-building process were transplantation center, year of transplantation, conditioning regimen, GVHD prophylaxis, recipient characteristics (age, sex, race, Karnofsky performance-status score [with scores ranging from 0 to 100 and higher scores indicat- ing better performance status], diagnosis, disease stage, time from diagnosis to transplantation, status with respect to cytomegalovirus [CMV] serologic testing and coexisting diseases), donor characteristics (age, sex, race, status with respect to CMV infection, and parity), and HLA matching. Post hoc HLA typing included high-resolution testing for HLA-A, B, C, and DRB1, and the degree of donor-recipient mismatching was defined with the use of these alleles, on the basis of work by Lee et al. ${ }^{17}$ Preplanned subgroup analyses of survival according to age, HLA matching, and disease

Table 1. Characteristics of the Patients, Donors, and Transplantation Regimens, According to Study Group.*

\begin{tabular}{|c|c|c|}
\hline Characteristic & $\begin{array}{c}\text { Bone Marrow } \\
(N=278)\end{array}$ & $\begin{array}{l}\text { Peripheral-Blood } \\
\text { Stem Cells } \\
(\mathrm{N}=\mathbf{2 7 3})\end{array}$ \\
\hline \multicolumn{3}{|l|}{ Diagnosis - no. (\%) } \\
\hline Acute myeloid leukemia & $130(47)$ & $131(48)$ \\
\hline First complete remission & $61(22)$ & $60(22)$ \\
\hline Second complete remission & $32(12)$ & $32(12)$ \\
\hline Third or subsequent complete remission & $5(2)$ & $3(1)$ \\
\hline Relapse & $32(12)$ & $36(13)$ \\
\hline Acute lymphoblastic leukemia & $61(22)$ & $56(21)$ \\
\hline First complete remission & $21(8)$ & $30(11)$ \\
\hline Second complete remission & $25(9)$ & $18(7)$ \\
\hline Third or subsequent complete remission & $5(2)$ & $1(0)$ \\
\hline Relapse & $10(4)$ & $7(3)$ \\
\hline Chronic myeloid leukemia & $29(10)$ & $37(14)$ \\
\hline Chronic phase & $20(7)$ & $24(9)$ \\
\hline Accelerated phase & $6(2)$ & $7(3)$ \\
\hline Blast phase & $3(1)$ & $6(2)$ \\
\hline Myelodysplastic syndrome & $52(19)$ & $41(15)$ \\
\hline Refractory anemia, RARS, or RCMD & $15(5)$ & $12(4)$ \\
\hline RAEB-1 or RAEB- $2 \dagger$ & $22(8)$ & $17(6)$ \\
\hline Other & $15(5)$ & $12(4)$ \\
\hline Chronic myelomonocytic leukemia & $4(1)$ & $4(1)$ \\
\hline Myelofibrosis & $2(1)$ & $4(1)$ \\
\hline High-risk disease - no. $(\%) \ddagger$ & $78(28)$ & $77(28)$ \\
\hline Age $>40 \mathrm{yr}-$ no. (\%) & $159(57)$ & $159(58)$ \\
\hline Male sex - no. (\%) & $168(60)$ & $146(53)$ \\
\hline White race - no. (\%) $\int$ & $250(90)$ & $248(91)$ \\
\hline Karnofsky performance-status score $\geq 90 \%$ - no./total no. (\%) $q$ & $172 / 240(72)$ & $154 / 228(68)$ \\
\hline Seropositivity for cytomegalovirus — no./total no. (\%) & $142 / 263(54)$ & $123 / 261(47)$ \\
\hline \multicolumn{3}{|l|}{ Conditioning regimen — no. (\%) } \\
\hline Cyclophosphamide and total-body irradiation $\|$ & $133(48)$ & $133(49)$ \\
\hline Cyclophosphamide and busulfan*** & $90(32)$ & $75(27)$ \\
\hline Fludarabine, busulfan, and antithymocyte globulin ${ }^{\prime} \dagger \dagger$ & $39(14)$ & $40(15)$ \\
\hline Fludarabine and melphalantt & $16(6)$ & $25(9)$ \\
\hline
\end{tabular}




\begin{tabular}{|c|c|c|}
\hline Characteristic & $\begin{array}{c}\text { Bone Marrow } \\
(\mathrm{N}=\mathbf{2 7 8})\end{array}$ & $\begin{array}{l}\text { Peripheral-Blood } \\
\text { Stem Cells } \\
(\mathrm{N}=\mathbf{2 7 3})\end{array}$ \\
\hline \multicolumn{3}{|l|}{ GVHD prophylaxis — no. (\%) } \\
\hline Cyclosporine and methotrexate & $67(24)$ & $59(22)$ \\
\hline Tacrolimus and methotrexate & $183(66)$ & $196(72)$ \\
\hline Other & $28(10)$ & $18(7)$ \\
\hline Did not undergo transplantation — no. (\%) & $14(5)$ & $11(4)$ \\
\hline Antithymocyte globulin treatment - no./total no. (\%) $\mathbb{\int} \sqrt{ }$ & $65 / 258(25)$ & $72 / 255(28)$ \\
\hline \multicolumn{3}{|c|}{ No. of donor mismatches at $H L A-A, B, C$, and DRB1 - no./total no. (\%) $\ \rrbracket$} \\
\hline 0 & $200 / 264(76)$ & $209 / 262(80)$ \\
\hline 1 & $55 / 264(21)$ & $50 / 262(19)$ \\
\hline 2 & $7 / 264(3)$ & $3 / 262(1)$ \\
\hline 3 & $2 / 264(1)$ & $0 / 262$ \\
\hline \multicolumn{3}{|l|}{ CD34+ cell dose per kilogram $\left(\times 10^{-6}\right)\|\|$} \\
\hline Median & 2.75 & 7.70 \\
\hline Interquartile range & $1.94-4.53$ & $5.43-11.28$ \\
\hline
\end{tabular}

* The CD34+ cell counts differed significantly between the two groups $(P<0.001)$. There were no other significant betweengroup differences. GVHD denotes graft-versus-host disease, RAEB refractory anemia with excess of blasts, RARS refractory anemia with ring sideroblasts, and RCMD refractory cytopenia with multilineage dysplasia.

$\dagger$ RAEB-1 is characterized by 5 to $9 \%$ blasts in bone marrow, and RAEB-2 by 10 to $19 \%$ blasts in bone marrow.

$\neq$ High-risk disease includes acute myeloid leukemia in third or subsequent remission or not in remission, acute lymphoblastic leukemia not in remission, the myelodysplastic syndrome with excess blasts in transformation, chronic myeloid leukemia in blast phase, and chronic myelomonocytic leukemia in any stage.

$\int$ Race was determined by the investigators.

9 Scores on the Karnofsky performance-status scale range from 0 to 100 , with higher scores indicating better performance status.

\| The required minimum doses for this conditioning regimen were cyclophosphamide at a dose of $120 \mathrm{mg}$ per kilogram of body weight and a fractionated total-body irradiation of $12 \mathrm{~Gy}$.

$* *$ The required minimum doses for this conditioning regimen were cyclophosphamide at a dose of $120 \mathrm{mg}$ per kilogram given intravenously and busulfan at a dose of $14 \mathrm{mg}$ per kilogram given orally or $11.2 \mathrm{mg}$ per kilogram given intravenously or an average targeted serum concentration greater than $600 \mathrm{ng}$ per milliliter.

t个 The required minimum doses for this conditioning regimen were fludarabine at a dose of $120 \mathrm{mg}$ per square meter of body-surface area and busulfan at a dose of $8 \mathrm{mg}$ per kilogram or $250 \mathrm{mg}$ per square meter. The protocol did not specify a minimum dose for antithymocyte globulin.

+ The required minimum doses for this conditioning regimen were fludarabine at a dose of $120 \mathrm{mg}$ per square meter and melphalan at a dose of $140 \mathrm{mg}$ per square meter.

If Data on treatment with antithymocyte globulin were not collected for patients who did not undergo transplantation. Data were also missing for several patients who did undergo transplantation.

91 Data on donor HLA mismatch were not collected for patients who did not undergo transplantation.

\|\| Data on CD34+ cell dose were missing for 121 patients (44\%) in the bone marrow group and $25(9 \%)$ in the peripheralblood group.

risk were conducted with the use of an interaction test in the Cox proportional-hazards model. The statistical analyses were performed with the use of SAS software, version 9.2 (SAS Institute).

\section{RESULTS}

CHARACTERISTICS OF THE PATIENTS AND DONORS

The characteristics of the patients and donors are shown in Table 1, along with details of the treatments. The bone marrow and peripheral-blood groups were well balanced with respect to age, sex, Karnofsky performance-status score, diagnosis, disease risk, positive result on serologic testing for CMV, and race. Patients were treated in 48 transplantation centers in the United States and Canada. Donors were from 54 National Marrow Donor Program-affiliated donor centers in the United States, Canada, and Germany. The proportion of donors who were fully matched for HLAA, B, C, and DRB1 and other donor characteristics were similar between the two study groups. 


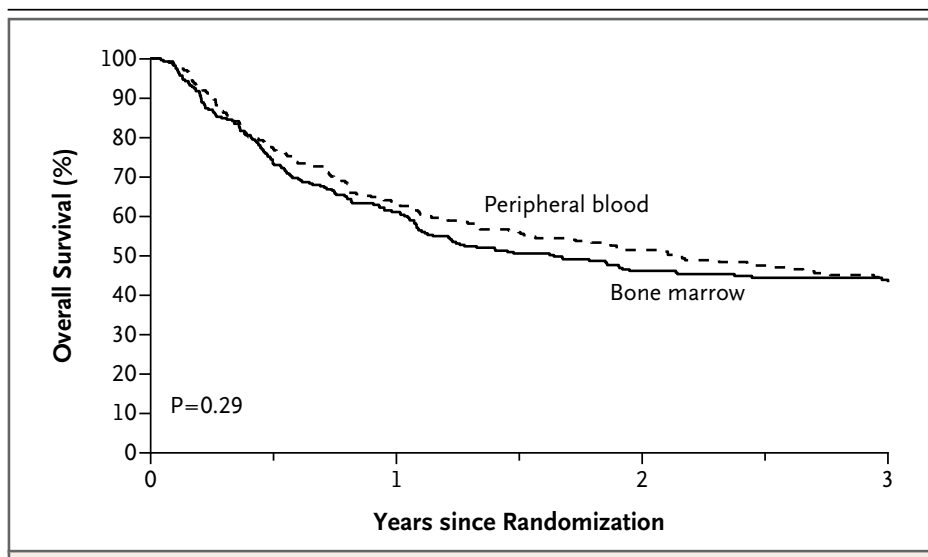

Figure 1. Survival after Randomization in the Intention-to-Treat Analysis.

The $P$ value is from a stratified binomial comparison at the 2-year point. The $P$ value from a stratified log-rank test was also not significant. A total of $75 \mathrm{pa}-$ tients in each group were still alive at 36 months.

\section{TREATMENT COMPLIANCE}

More than $90 \%$ of the patients received a transplant from the assigned graft source. Five percent of the patients randomly assigned to the bone marrow group and $4 \%$ of those randomly assigned to the peripheral-blood group did not undergo transplantation but were included in the intentionto-treat analysis. The primary reason for not undergoing transplantation (accounting for $84 \%$ of these patients) was relapse of cancer. Twelve patients $(4 \%)$ randomly assigned to the bone marrow group received peripheral-blood stem cells owing to concern that a bone marrow harvest would delay the transplantation (six patients) or because of a preference of the donor (four) or physician (two). One patient $(<1 \%)$ randomly assigned to the peripheral-blood group received bone marrow because of donor preference. Overall, $98 \%$ of the patients received the conditioning regimen and GVHD prophylaxis chosen before randomization by the physician in charge of the transplantation.

\section{INTENTION-TO-TREAT ANALYSIS}

The primary end point was the overall survival rate at 2 years according to an intention-to-treat analysis. The 2-year overall survival rate in the peripheral-blood group was $51 \%$ ( $95 \%$ confidence interval [CI], 45 to 57), as compared with $46 \%$ (95\% CI, 40 to 52) in the bone marrow group (stratified odds ratio, 1.20 ; $95 \%$ CI, 0.85 to 1.70 ; $\mathrm{P}=0.29$ ) (Fig. 1). The absolute difference in overall survival at 2 years was 5 percentage points (95\% CI, -3 to 14 ).
Figure 2 (facing page). Outcomes after Transplantation, According to Study Group.

Panel A shows the rate of overall survival, and Panel B the rate of disease-free survival. Panel $C$ shows the incidence of death unrelated to relapse. Panel $D$ shows the incidence of relapse. Panel $E$ shows the incidence of neutrophil engraftment ( $>500$ neutrophils per cubic millimeter), and Panel $F$ the incidence of platelet engraftment $(>20,000$ platelets per cubic millimeter, without platelet transfusion during the prior 7 days). Panel $G$ shows the incidence of acute graft-versus-host disease (GVHD) of grades II to IV, and Panel $\mathrm{H}$ the incidence of chronic GVHD. P values for the between-group differences in overall survival (Panel $A$ ) and disease-free survival (Panel B) are from a stratified binomial comparison at the 2-year point; $P$ values from stratified log-rank tests for survival and disease-free survival were also not significant. All other $P$ values shown are from stratified log-rank tests.

\section{SURVIVAL AND RELAPSE AFTER TRANSPLANTATION}

The following analyses were restricted to patients who received the transplant. The rate of overall survival at 2 years after transplantation did not differ significantly in pointwise comparisons between the group randomly assigned to receive peripheral blood and the group assigned to receive bone marrow (estimated difference of 4 percentage points; $95 \% \mathrm{CI},-4$ to $13 ; \mathrm{P}=0.33$ ) (Fig. 2A); neither did the rate of disease-free survival at 2 years (estimated difference of 3 percentage points; $95 \% \mathrm{CI}$, -5 to $12 ; \mathrm{P}=0.38$ ) (Fig. 2B). Mortality unrelated to relapse was similar at 2 years in the two treatment groups (estimated difference of 2 percentage points; $95 \% \mathrm{CI},-6$ to $9 ; \mathrm{P}=0.66$ ) (Fig. $2 \mathrm{C}$ ), as was the rate of relapse (estimated difference of 1 percentage point; $95 \% \mathrm{CI},-7$ to 9 ; $\mathrm{P}=0.74$ ) (Fig. 2D). A sensitivity analysis that was performed with the use of multivariate Cox models with adjustment for age, disease risk, HLA matching, status with regard to the diffusing capacity of the lung for carbon monoxide, and conditioning regimen also showed similar results for overall survival and disease-free survival ( $\mathrm{P}=0.70$ and $\mathrm{P}=0.71$, respectively). As expected, younger recipient age, low disease risk, and HLA matching of the donor (eight of the eight HLA alleles vs. seven of the eight) were associated with increased survival, but these variables had no interaction with stem-cell source (data not shown).

\section{REPORTED ADVERSE EVENTS}

The frequency of reported adverse events did not differ significantly between the two groups (Table S1 in the Supplementary Appendix, available at 


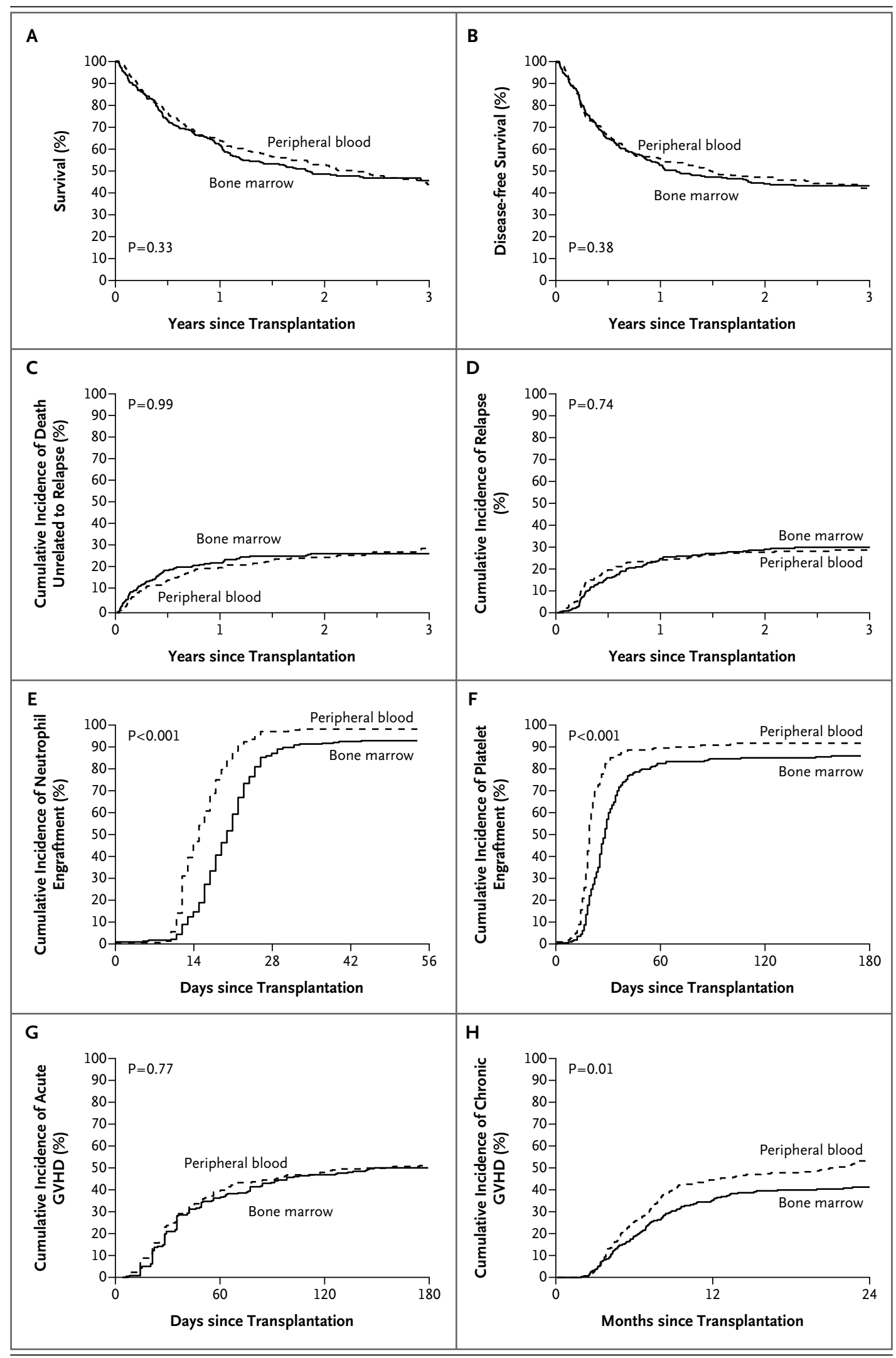

N ENGLJ MED 367;16 NEJM.ORG OCTOBER 18, 2012

The New England Journal of Medicine

Downloaded from nejm.org at VIRGINIA COMMONWEALTH UNIV on January 13, 2015. For personal use only. No other uses without permission. Copyright (C) 2012 Massachusetts Medical Society. All rights reserved. 
NEJM.org). The median duration of the first hospitalization for the transplantation was 5 days shorter among patients who received peripheralblood stem cells than among those who received bone marrow $(\mathrm{P}<0.001)$, but the median number of days that transplant recipients were hospitalized during the first year of the study was similar in the two groups (37 days in each group, $\mathrm{P}=0.41$ ).

\section{ENGRAFTMENT}

Among patients randomly assigned to receive peripheral-blood stem cells, as compared with those randomly assigned to receive bone marrow, the median time to neutrophil engraftment was 5 days shorter $(\mathrm{P}<0.001)$, and the median time to platelet engraftment was 7 days shorter $(\mathrm{P}<0.001)$ (Fig. 2E and 2F). Primary graft failure occurred in $2 \%$ of the patients randomly assigned to receive peripheral-blood stem cells and in 6\% of those randomly assigned to receive bone marrow; secondary graft failure occurred in $1 \%$ and $3 \%$ of patients, respectively. The total incidence of graft failure was $3 \%$ ( $95 \%$ CI, 1 to 5 ) in the peripheralblood group and 9\% (95\% CI, 6 to 13) in the bone marrow group ( $\mathrm{P}=0.002)$. The between-group difference in the incidence of all graft failures was 7 percentage points (95\% CI, 2 to $11 ; \mathrm{P}=0.002$ ).

\section{ACUTE AND CHRONIC GVHD}

The rate of acute GVHD of grades II to IV (Fig. $2 \mathrm{G}$ ) and the rate of grade III or IV disease (data not shown) were similar in the two groups. The incidence of chronic GVHD at 2 years was significantly higher in the peripheral-blood group than in the bone marrow group (53\% [95\% CI, 45 to 61 ] vs. $41 \%$ [ $95 \% \mathrm{CI}, 34$ to 48 ], $\mathrm{P}=0.01$ by the stratified log-rank test) (Fig. 2H). The difference in the incidence of chronic GVHD at 2 years was 12 percentage points ( $95 \%$ CI, 2 to 22). The proportion of patients with extensive chronic GVHD was higher in the peripheral-blood group than in the bone marrow group (48\% [95\% CI, 42 to 54] vs. $32 \%$ [95\% CI, 26 to 38], P<0.001). Among patients who were alive at 2 years, $57 \%$ of the patients in the peripheral-blood group were receiving immunosuppressive therapy, as compared with $37 \%$ of those in the bone marrow group $(\mathrm{P}=0.03)$.

\section{CAUSES OF DEATH}

There was no significant between-group difference in the proportion of deaths from infection or relapse. Deaths attributed to chronic GVHD were more common in the peripheral-blood group, whereas deaths attributed to graft failure were more common in the bone marrow group $(\mathrm{P}=0.002)$ (Table 2). Acute and chronic GVHD were the predominant causes of deaths unrelated to relapse in both groups.

\section{I SCUSSION}

This large, multicenter, randomized trial did not show a significant survival difference between transplant recipients who received peripheralblood stem cells and those who received bone marrow from unrelated donors. Results were similar among HLA-mismatched pairs, recipients with advanced disease, and recipients older than 40 years of age, although this trial was not powered to detect potential differences within these subsets. Other transplantation outcomes, including relapse rates, mortality unrelated to relapse, and rates of acute GVHD, were also similar with the two types of grafts, except that peripheral-blood stem-cell transplants were associated with better engraftment and bone marrow transplants with less extensive chronic GVHD.

Our study was not powered to support firm conclusions on several issues of interest. However, it is possible to make some testable inferences from our results. These results show that although the two graft sources are associated with similar survival rates after transplantation, specific characteristics of the patients may suggest the preferential use of peripheral-blood stem cells or bone marrow. Peripheral-blood stem cells may be recommended for patients at higher risk for graft failure. ${ }^{18-20}$ For example, patients with malignant diseases who have never undergone cytotoxic chemotherapy may be at increased risk for rejection of a bone marrow graft and might benefit from peripheralblood stem cells. ${ }^{21}$ Bone marrow may be recommended for all other patients, especially those who are immunosuppressed owing to prior chemotherapy, since they have a lower risk of graft rejection. For all patients, the use of bone marrow will decrease the risk of chronic GVHD.

Donor preference may also affect the choice of stem-cell source. In our trial, $30 \%$ of screened donors declined to undergo randomization, preferring one donation source over the other. Donors who participated in the trial and were randomly assigned to donate bone marrow reported more discomfort early after the donation, but 
symptoms at 8 weeks were similar to those in the peripheral-blood stem-cell donors. ${ }^{22}$ The acquisition costs are similar for peripheral-blood stem cells and bone marrow, according to the National Marrow Donor Program fee schedule, and therefore, graft-acquisition costs should not affect the choice of stem-cell source. ${ }^{12}$

The present study included patients with leukemia or chronic myeloid disorders, $78 \%$ of whom were treated with myeloablative conditioning regimens, and the results may not be generalizable to other clinical situations. For example, reducedintensity regimens, including very-low-dose, nonmyeloablative conditioning regimens, are now commonly used in patients older than 50 years of age and in those with serious coexisting diseases. ${ }^{23}$ We did not find significant interactions between graft sources and the intensity of the conditioning regimen, but the range of intensity was narrow. Nonmyeloablative regimens were not allowed, and only $22 \%$ of the patients underwent a reduced-intensity regimen. Nonmyeloablative and reduced-intensity conditioning regimens provide less intensive immunosuppression, and the stronger engraftment potential associated with peripheral-blood stem-cell transplantation could be advantageous in this situation.

Our results differ somewhat from the findings in studies of transplantation from HLA-identical siblings. In some of these studies, the use of peripheral-blood stem cells improved survival among patients with advanced disease, predominantly by decreasing the risk of relapse. ${ }^{24,25}$ This discrepancy may be due to differences in the study populations. Chronic myeloid leukemia is the disease most sensitive to the antileukemia effect of peripheral-blood stem-cell transplantation from siblings. Patients with chronic myeloid leukemia accounted for only $12 \%$ of our study population, as compared with 40 to $50 \%$ of patients in the sibling trials, probably because imatinib and other similar drugs had been approved for use in the interim. ${ }^{24-26}$ It is also possible that increased mortality from chronic GVHD among recipients of peripheral-blood stem cells from unrelated donors offsets the benefits associated with the more rapid and robust engraftment that occurs with peripheral-blood stem cells, as compared with bone marrow. ${ }^{27,28}$ Given the greater genetic disparity between unrelated donors and recipients, current regimens for GVHD prophylaxis may not adequately counteract the increased risk

\begin{tabular}{llc|}
$\begin{array}{l}\text { Table 2. Primary Causes of Death among Patients Who } \\
\text { Underwent Transplantation.* }\end{array}$ & $\begin{array}{c}\text { Peripheral-Blood } \\
\text { Stem Cells } \\
\text { (N=145) }\end{array}$ \\
Cause of Death & $\begin{array}{c}\text { Bone Marrow } \\
\text { (N=145) }\end{array}$ & $\begin{array}{c}\text { number (percent) } \\
\text { Relapse }\end{array}$ \\
Infection & $73(50)$ & $69(48)$ \\
Graft failure & $13(9)$ & $8(6)$ \\
Acute GVHD & $11(8)$ & 0 \\
Chronic GVHD & $20(14)$ & $24(17)$ \\
Other & $14(10)$ & $30(21)$ \\
\end{tabular}

$* \mathrm{P}=0.002$ for the overall comparison between the groups. Percentages do not add up to 100 because of rounding.

of GVHD that is associated with the higher numbers of $\mathrm{T}$ cells in peripheral-blood stem cells.

In conclusion, the rates of survival, relapse, and acute GVHD are similar with bone marrow and peripheral-blood stem-cell grafts from unrelated donors, but engraftment is better with peripheral-blood stem cells and the rate of chronic GVHD is lower with bone marrow. In addition to the relevance of these findings to the selection of a graft source for transplantation from unrelated donors, our results suggest that there is a need to develop transplantation approaches that decrease the risk of graft failure when bone marrow is used and that decrease the risks of acute and extensive chronic GVHD when either stem-cell source is used. Antilymphocyte globulin has shown promise in preventing moderateto-severe chronic GVHD after transplantation from an unrelated donor. ${ }^{29,30}$ Alternatively, hematopoietic cells collected from bone marrow after donor treatment with growth factors may facilitate engraftment without increasing the risk of GVHD. 9 Prospective randomized clinical trials are comparing this stem-cell source with unstimulated bone marrow or mobilized peripheralblood stem cells in recipients of transplants from HLA-identical siblings.

The views expressed in this article are those of the authors and do not reflect the views or the official policy or position of the National Heart, Lung, and Blood Institute, the National Cancer Institute, or the National Marrow Donor Program.

Supported by a grant from the National Heart, Lung, and Blood Institute and the National Cancer Institute (U10HL069294), by the Office of Naval Research, and by the National Marrow Donor Program.

Disclosure forms provided by the authors are available with the full text of this article at NEJM.org. 
We thank the transplantation-center teams in the United States and Canada for enrolling patients in this trial (see Table S2 in the Supplementary Appendix); the donor-center teams in the United States, Canada, and Germany for recruiting the donors for the trial (see Table S3 in the Supplementary Appendix); and the National Marrow Donor Program coordinating center for facilitating the transplantations.

REFERENCES

1. Russell NH, Hunter A, Rogers S, Hanley J, Anderson D. Peripheral blood stem cells as an alternative to marrow for allogeneic transplantation. Lancet 1993;341: 1482.

2. Dreger P, Suttorp M, Haferlach T, Löffler H, Schmitz N, Schroyens W. Allogeneic granulocyte colony-stimulating factormobilized peripheral blood progenitor cells for treatment of engraftment failure after bone marrow transplantation. Blood 1993; 81:1404-7.

3. Körbling M, Przepiorka D, Huh YO, et al. Allogeneic blood stem cell transplantation for refractory leukemia and lymphoma: potential advantage of blood over marrow allografts. Blood 1995;85:1659-65.

4. Schmitz N, Dreger P, Suttorp M, et al. Primary transplantation of allogeneic peripheral blood progenitor cells mobilized by filgrastim (granulocyte colony-stimulating factor). Blood 1995;85:1666-72.

5. Bensinger WI, Weaver $\mathrm{CH}$, Appelbaum FR, et al. Transplantation of allogeneic peripheral blood stem cells mobilized by recombinant human granulocyte colonystimulating factor. Blood 1995;85:1655-8. 6. Blaise D, Kuentz M, Fortanier C, et al. Randomized trial of bone marrow versus lenograstim-primed blood cell allogeneic transplantation in patients with earlystage leukemia: a report from the Société Française de Greff e de Moelle. J Clin Oncol 2000;18:537-46.

7. Powles R, Mehta J, Kulkarni S, et al. Allogeneic blood and bone-marrow stemcell transplantation in haematological malignant diseases: a randomised trial. Lancet 2000;355:1231-7.

8. Bensinger WI, Martin PJ, Storer B, et al. Transplantation of bone marrow as compared with peripheral-blood cells from HLA-identical relatives in patients with hematologic cancers. N Engl J Med 2001;344:175-81.

9. Morton J, Hutchins C, Durrant S. Granulocyte-colony-stimulating factor (G-CSF)-primed allogeneic bone marrow: significantly less graft-versus-host disease and comparable engraftment to G-CSFmobilized peripheral blood stem cells. Blood 2001;98:3186-91.

10. Couban S, Simpson DR, Barnett MJ, et al. A randomized multicenter comparison of bone marrow and peripheral blood in recipients of matched sibling allogeneic transplants for myeloid malignancies. Blood 2002;100:1525-31.

11. Schmitz N, Beksac M, Hasenclever D, et al. Transplantation of mobilized pe- ripheral blood cells to HLA-identical siblings with standard-risk leukemia. Blood 2002;100:761-7.

12. National Marrow Donor Program homepage (http://www.marrow.org).

13. Eapen M, Logan BR, Confer DL, et al Peripheral blood grafts from unrelated donors are associated with increased acute and chronic graft-versus-host disease without improved survival. Biol Blood Marrow Transplant 2007;13:1461-8. 14. Lin DY. Non-parametric inference for cumulative incidence functions in competing risks. Stat Med 1997;16:901-10. 15. Shulman HM, Sullivan KM, Weiden PL, et al. Chronic graft-versus-host syndrome in man: a long-term clinicopathologic study of 20 Seattle patients. Am J Med 1980;69:204-17.

16. Filipovich $\mathrm{AH}$, Weisdorf $\mathrm{D}$, Pavletic $\mathrm{S}$, et al. National Institutes of Health consensus development project on criteria for clinical trials in chronic graft-versus-host disease: I. Diagnosis and staging working group report. Biol Blood Marrow Transplant 2005;11:945-56.

17. Lee SJ, Klein J, Haagenson $M$, et al. High-resolution donor-recipient HLA matching contributes to the success of unrelated donor marrow transplantation. Blood 2007;110:4576-83.

18. Sierra J, Storer B, Hansen JA, et al. Transplantation of marrow cells from unrelated donors for treatment of high-risk acute leukemia: the effect of leukemic burden, donor HLA-matching, and marrow cell dose. Blood 1997;89:4226-35.

19. Petersdorf EW, Hansen JA, Martin PJ, et al. Major-histocompatibility-complex class I alleles and antigens in hematopoietic-cell transplantation. $\mathrm{N}$ Engl J Med 2001;345:1794-800.

20. Spellman S, Bray R, Rosen-Bronson S, et al. The detection of donor-directed, HLA-specific alloantibodies in recipients of unrelated hematopoietic cell transplantation is predictive of graft failure. Blood 2010;115:2704-8.

21. Guardiola P, Runde V, Bacigalupo A et al. Retrospective comparison of bone marrow and granulocyte colony-stimulating factor-mobilized peripheral blood progenitor cells for allogeneic stem cell transplantation using HLA identical sibling donors in myelodysplastic syndromes. Blood 2002;99:4370-8.

22. Switzer GE, Harrington D, Haagenson $\mathrm{MD}$, et al. Health-related quality-of-life among adult matched unrelated stem cell donors: a Blood and Marrow Transplant
Clinical Trials Network (BMT CTN) randomized trial of marrow versus PBSC donation. Presented at the 52nd ASH Annual Meeting and Exposition, Orlando, FL, December 4-7, 2010. abstract.

23. Pasquini MC, Wang $Z$, Horowitz MM, Gale RP. 2010 Report from the Center for International Blood and Marrow Transplant Research (CIBMTR): current uses and outcomes of hematopoietic cell transplants for blood and bone marrow disorders. Clin Transpl 2010;2010:87-105.

24. Stem Cell Trialists' Collaborative Group. Allogeneic peripheral blood stemcell compared with bone marrow transplantation in the management of hematologic malignancies: an individual patient data meta-analysis of nine randomized trials. J Clin Oncol 2005;23:5074-87.

25. Pidala J, Anasetti C, Kharfan-Dabaja MA, Cutler C, Sheldon A, Djulbegovic B. Decision analysis of peripheral blood versus bone marrow hematopoietic stem cells for allogeneic hematopoietic cell transplantation. Biol Blood Marrow Transplant 2009;15:1415-21.

26. Oehler VG, Radich JP, Storer B, et al. Randomized trial of allogeneic related bone marrow transplantation versus peripheral blood stem cell transplantation for chronic myeloid leukemia. Biol Blood Marrow Transplant 2005;11:85-92.

27. Flowers ME, Parker PM, Johnston LJ, et al. Comparison of chronic graft-versushost disease after transplantation of peripheral blood stem cells versus bone marrow in allogeneic recipients: long-term follow-up of a randomized trial. Blood 2002;100:415-9.

28. Friedrichs B, Tichelli A, Bacigalupo A, et al. Long-term outcome and late effects in patients transplanted with mobilised blood or bone marrow: a randomised trial. Lancet Oncol 2010;11:331-8.

29. Bacigalupo A, Lamparelli T, Barisione G, et al. Thymoglobulin prevents chronic graft-versus-host disease, chronic lung dysfunction, and late transplant-related mortality: long-term follow-up of a randomized trial in patients undergoing unrelated donor transplantation. Biol Blood Marrow Transplant 2006;12:560-5.

30. Finke J, Bethge WA, Schmoor C, et al. Standard graft-versus-host disease prophylaxis with or without anti-T-cell globulin in haematopoietic cell transplantation from matched unrelated donors: a randomised, open-label, multicentre phase 3 trial. Lancet Oncol 2009;10:855-64.

Copyright @ 2012 Massachusetts Medical Society. 